\title{
Conformation, Self-Organization and Thermoresponsibility of Polymethacrylate Molecular Brushes with Oligo(ethylene glycol)-block-oligo(propylene glycol) Side Chains
}

\author{
Maria Simonova $^{1, *}$, Denis Kamorin ${ }^{2,3}$, Oleg Kazantsev ${ }^{2}$, Maria Nepomnyashaya ${ }^{4}$ and Alexander Filippov ${ }^{1}$ \\ 1 Institute of Macromolecular Compounds of the Russian Academy of Sciences, Bolshoy Prospekt 31, \\ 199004 Saint Petersburg, Russia; afil@imc.macro.ru \\ 2 Laboratory of Acrylic Monomers and Polymers, Department of Chemical Technology, Dzerzhinsk \\ Polytechnic Institute, Nizhny Novgorod State Technical University n.a. R.E. Alekseev, 24 Minin Street, \\ 603950 Nizhny Novgorod, Russia; d.kamorin@mail.ru (D.K.); kazantsev@dpingtu.ru (O.K.) \\ 3 Chromatography Laboratory, Department of Production Control and Chromatography Methods, \\ Lobachevsky State University of Nizhni Novgorod, Dzerzhinsk Branch, 23 Prospekt Gagarina, \\ 603950 Nizhny Novgorod, Russia \\ 4 Higher School of Technology and Energy, Ivana Chernykh 4, 198095 Saint Petersburg, Russia; \\ marinepom@mail.ru \\ * Correspondence: mariasimonova1983@mail.ru; Tel.: +7-812-328-4102
}

\section{check for}

updates

Citation: Simonova, M.; Kamorin, D.; Kazantsev, O.; Nepomnyashaya, M.; Filippov, A. Conformation, Self-Organization and Thermoresponsibility of Polymethacrylate Molecular Brushes with Oligo(ethylene glycol)-blockoligo(propylene glycol) Side Chains. Polymers 2021, 13, 2715. https:// doi.org/10.3390/polym13162715

Academic Editor: Gregory T. Russell

Received: 23 July 2021

Accepted: 9 August 2021

Published: 13 August 2021

Publisher's Note: MDPI stays neutral with regard to jurisdictional claims in published maps and institutional affiliations.

Copyright: (c) 2021 by the authors. Licensee MDPI, Basel, Switzerland. This article is an open access article distributed under the terms and conditions of the Creative Commons Attribution (CC BY) license (https:// creativecommons.org/licenses/by/ $4.0 /)$.
Abstract: Polymethacrylic molecular brushes with oligo(ethylene glycol)-block-oligo(propylene glycol) side chains were investigated by static and dynamic light scattering and viscometry. The solvents used were acetonitrile, tetrahydrofuran, chloroform, and water. The grafted copolymers were molecularly dispersed and dissolved in tetrahydrofuran and acetonitrile. In these solvents, the molar masses of copolymers were determined. In thermodynamically good solvents, namely tetrahydrofuran and acetonitrile, investigated copolymers have a high intramolecular density and the shape of their molecules resembles a star-shaped macromolecule. In chloroform and water, the micelle-like aggregates were formed. Critical micelle concentrations decreased with the lengthening of the hydrophobic block. Molecular brushes demonstrated thermosensitive behavior in aqueous solutions. The phase separation temperatures reduced with an increase in the content of the oligo(propylene glycol) block.

Keywords: molecular brushes; radical polymerization; thermoresponsive polymers; methoxy (oligoethylene glycol-block-oligopropylene glycol) methacrylates; oligo(ethylene glycol) methacrylates; oligo(propylene glycol) methacrylates

\section{Introduction}

Polymers with complex architecture attract a significant amount of attention due to the wide possibilities of regulating their characteristics by the variation of the structure and the architecture parameters [1,2]. In the case of molecular brushes, these parameters are the chemical structure of the backbone and side chains, their sizes, and the grafting density of the grafted chains. The introduction of functional groups into the main and/or side chains is also used. The modern synthetic approaches make it possible to obtain grafted copolymers with an ordained molecular architecture and controlled molar mass.

Thermoresponsive molecular brushes are of special interest because they are used in various fields-for example, in medicine and biotechnology, in solving environmental problems, etc. [3,4] A significant number of molecular brushes are amphiphilic systems since they are built from components with different chemical natures. Therefore, they may adopt a wide variety of conformations in selective solvents $[5,6]$. The behavior of their solutions is influenced importantly by the different thermodynamic qualities of the solvent being used with respect to the backbone and side chains. Moreover, the architecture 
parameters of grafted copolymers strongly affect the solubility and the assembly behavior of macromolecules compared to linear diphilic block-copolymers [7-10]. For example, the shape of the molecules of dense amphiphilic brushes in a thermodynamically poor solvent for the backbone resembles a star-shaped molecule, the core of which is a collapsed main chain, and the grafted chains are arms [11-14] A decrease in the grafting density of the side chains leads to a decline in solubility and to aggregate formation due to the interaction of insoluble components $[15,16]$. In particular, diphilic molecular brushes are able to form ordered micellar structures by the self-assembly processes of macromolecules in selective solvents.

A large number of works are devoted to the analysis of the stimulus sensitivity of molecular brushes $[12,13,17]$. However, the number of systematic studies of the concrete classes of polymer brushes is not very large. The effects of the structure of components, their fraction, grafting density, and molar masses on self-organization and phase separation temperatures are analyzed. The role of side chain grafting density $\mathrm{z}$ in the formation of the properties of aqueous solutions was established for the grafted copolymers with an alkylene-aromatic polyester backbone and side poly(2-ethyl-2-oxazoline) chains [18]. The decrease in $\mathrm{z}$ facilitates the contacts of the backbones of different macromolecules. In the solution of copolymer with low $\mathrm{z}$, the aggregate dimensions were larger than those in the case of brushes with high grafting density. The phase separation temperature reduced with a decrease in z. Moreover, at low temperatures, the aggregation is the dominating process in the solution of low grafting density copolymers, while for brushes with high $z$, the compaction of macromolecules and aggregates prevailed.

Amphiphilic copolymers containing methoxy oligo(ethylene glycol) methacrylates (MOEGM) have been intensively studied over the last 20 years $[19,20]$. Biocompatible MOEGM polymers are considered to be drug delivery polymers [19-24]. The influence of the structure of such copolymers on solution behavior, self-organization, and association have been investigated [25-28]. Recently, it has been shown that copolymers of MOEGM with higher alkyl methacrylates formed unimolecular micelles in aqueous solutions [29-33]. The thermoresponsive behavior of this type of polymers has also been demonstrated. The synthesis of polymer molecular brushes based on diblock macromonomers (methoxy (oligo(ethylene glycol)e-block-oligo(propylene glycol) $)_{\mathrm{p}}$ ) methacrylates, OEGeOPGpMA) with different lengths of oligo(ethylene glycol) (e) and oligo(propylene glycol) (p) moieties was reported recently [34]. The effects of synthesis conditions on the polymerization rates, maximum conversions, molar masses, and polydispersity have been analyzed.

The aim of this work is to investigate the effect of oligo(ethylene glycol) and oligo (propylene glycol) block lengths in polymers on the molecular and hydrodynamic characteristics of molecular dispersity solutions and the behavior of aqueous solutions (selforganization and thermoresponsibility) of polymethacrylic molecular brushes with oligo (ethylene glycol)-block-oligo(propylene glycol) side chains. The structures of the investigated polymers are presented in Figure 1.
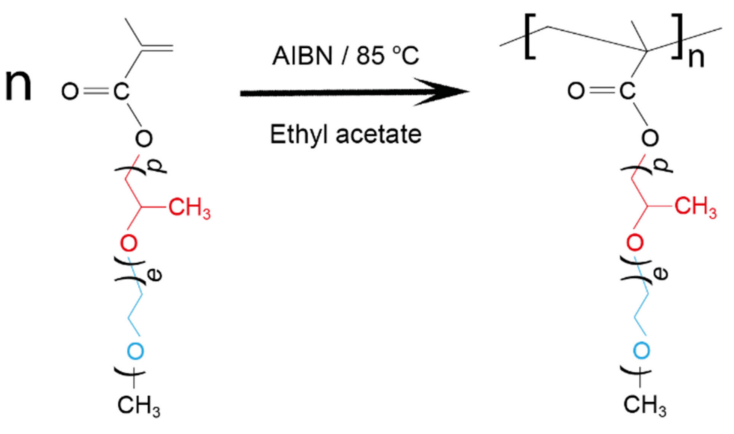

$\mathrm{OEG}_{\mathrm{e}} \mathrm{OPG} \mathrm{pMA}$

polyOEGeOPGpMA

Figure 1. Structures of the studied polymer brushes. 


\section{Materials and Methods}

\subsection{Copolymer Synthesis}

The "grafting through" method was used to produce polymers with a brush structure. The synthesis of the polymer brushes by the "grafting through" method implies a one-step process using macromonomers capable of radical polymerization. Three macromonomers with different oligo(ethylene glycol) (OEG) and oligo(propylene glycol) (OPG) block lengths were used to obtain polymers (Dzerzhinsk Polytechnic Institute, Dzerzhinsk, Russia; SigmaAldrich, Saint Louis, MO, USA). We used OEGeOPGpMA with the following average lengths of oligo(ethylene glycol) (e) and oligo(propylene glycol) (p) fragments: $\mathrm{e}=7.0$ and $\mathrm{p}=2.8$ in copolymer E7P3, $\mathrm{e}=7.0$ and $\mathrm{p}=5.4$ in brush E7P5, and $\mathrm{e}=7.0$ and $\mathrm{p}=10.3$ in sample E7P10 (Dzerzhinsk Polytechnic Institut, Dzerzhinsk, Russia). Polymers were synthesized by the conventional free-radical polymerization in organic solvents at $60-85^{\circ} \mathrm{C}$. The synthesis procedure of OEGeOPGpMAs was described in detail previously [34].

The structure of the polyOEGeOPGpMA samples was confirmed by nuclear magnetic resonance (NMR) spectroscopy (DDR2 400; Agilent, Santa Clara, CA, USA) in DMSO-D6 (Figure S1 in Supplementary Materials).

\subsection{Methods Molecular Hydrodynamics and Optics}

The initial characterization of the OEGeOPGpMA copolymers was carried out by gel permeation chromatography using a Chromos LC-301 (Chromos Engineering Co. Ltd., Dzerzhinsk, Russia) instrument with isocratic pump, refractometric detector and two exclusive columns Phenogel 5u 50A (Phenomenex, Torrance, CA, USA). Tetrahydrofuran (THF) was used as a mobile phase. Polystyrene calibration was used to calculate the molar masses of polymers, Supplementary Materials, Figure S2.

The solutions of polyOEGeOPGpMA (3 samples) were studied by molecular hydrodynamics and optics. The static (SLS) and dynamic light scattering (DLS) experiments were carried out using a Photocor Complex instrument (Photocor Instruments Inc., Moscow, Russia). The light source was the Photocor-DL diode laser with the wavelength $\lambda=659.1$ $\mathrm{nm}$ and controllable power up to $30 \mathrm{~mW}$. The correlation function of the scattered light intensity was obtained using the Photocor-PC2 correlator with 288 channels and processed using the DynalS software (ver. 8.2.3, SoftScientific, Tirat Carmel, Israel). Toluene was used as a calibration liquid, whose absolute scattering intensity is equal to $1.38 \times 10^{-5} \mathrm{~cm}^{-1}$. The measurements were performed at scattering angles $\theta$ in the range $45-135^{\circ}$.

Chloroform (density $\rho_{0}=1.486 \mathrm{~g} \cdot \mathrm{cm}^{-3}$, dynamic viscosity $\eta_{0}=0.57 \mathrm{cP}$, and refractive index $\left.n_{0}=1.443\right)$, TGF $\left(\rho_{0}=0.890 \mathrm{~g} \cdot \mathrm{cm}^{-3}, \eta_{0}=0.46 \mathrm{cP}\right.$, and $\left.n_{0}=1.405\right)$, acetonytryle $\left(\rho_{0}=1.486 \mathrm{~g} \cdot \mathrm{cm}^{-3}, \eta_{0}=0.57 \mathrm{cP}\right.$, and $\left.n_{0}=1.443\right)$, and water $\left(\rho_{0}=1.000 \mathrm{~g} \cdot \mathrm{cm}^{-3}, \eta_{0}=0.98 \mathrm{cP}\right.$, and $n_{0}=1.333$ ) were used as solvent (Sigma-Aldrich, Saint Louis, MO, USA). The values were determined at $25^{\circ} \mathrm{C}$.

For all solutions, the DLS recorded a unimodal particle size distribution, i.e., there was one type of particle in all of the solvents (Figure 2). This behavior is in agreement with the chromatographic data (Supplementary Materials, Figure S2). The values of the hydrodynamic radii $R_{\mathrm{h}-\mathrm{D}}(c)$ at given concentration $c$ were determined in the wide concentration range and extrapolated to zero concentration to obtain the hydrodynamic radius $R_{\mathrm{h}-\mathrm{D}}$ of macromolecules (Supplementary Materials, Figure S3). The translation diffusion coefficients $D_{0}$ and friction coefficient $f$ were obtained using Stokes-Einstein equations:

$$
D_{0}=k_{\mathrm{B}} T / f=k_{\mathrm{B}} T /\left(6 \pi \eta_{0} R_{\mathrm{h}-\mathrm{D}}\right)
$$

where $k_{\mathrm{B}}$ is Boltzmann's constant and $T$ is absolute temperature. 


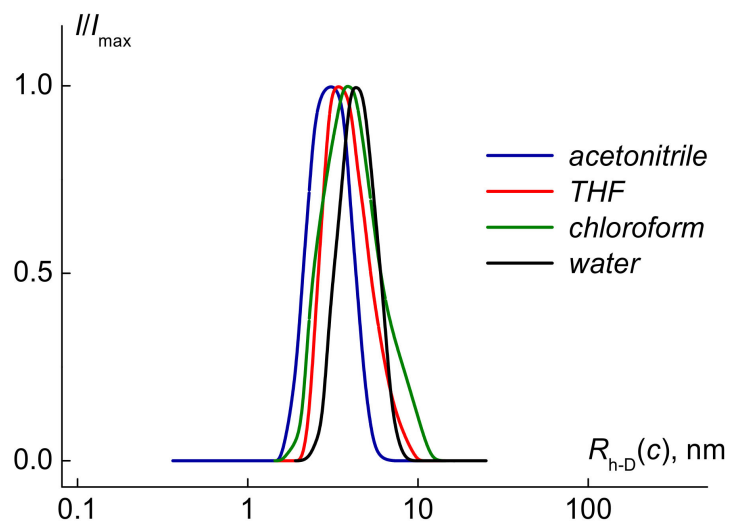

Figure 2. The hydrodynamic radii distribution for the solution of polyE7P10 at concentration $\mathrm{c} \approx 0.005 \mathrm{~g} \cdot \mathrm{cm}^{-3} \cdot I_{\max }$ is the maximum intensity of scattered light for the given solution concentration.

In all solutions, the asymmetry of the light scattering intensity was not observed for all copolymers. Therefore, the gyration radii of scattering objects could not be determined, and polymer molar masses $M_{\mathrm{w}}$ were obtained by the Debye method (angle $90^{\circ}$ ), using the formula

$$
\frac{c H}{I_{90}}=\frac{1}{M_{w}}+2 A_{2} c
$$

where $A_{2}$ is second virial coefficient and $H$ is the optical constant:

$$
H=\frac{4 \pi^{2} n_{0}^{2}(d n / d c)^{2}}{N_{\mathrm{A}} \lambda_{0}^{4}}
$$

Here, $I_{90}$ is the excessive intensity of light scattered at an angle of $90^{\circ}, N_{\mathrm{A}}$ is Avogadro's number, and $d n / d c$ is the refractive index increment. The values of $d n / d c$ were determined using an RA-620 refractometer (KEM, Kyoto, Japan) with a wavelength $\lambda_{0}=589.3 \mathrm{~nm}$. The values of $d n / d c$ were calculated from the slope of concentration dependences of the difference $\Delta n=n-n_{0}$ between the refractive indexes of the solution $n$ and the solvent $n_{0}$. The Debye plots for the investigated solutions are shown in Figure S4 (Supplementary Materials). Note that acetonitrile was thermodynamically good for all polymer samples (the second virial coefficient was positive). The values $M_{\mathrm{w}}$ and $R_{\mathrm{h}-\mathrm{D}}$ are shown in Table 1 .

\begin{tabular}{|c|c|c|c|c|c|}
\hline Solvent & $M_{\mathrm{w}}, \mathrm{g} \cdot \mathrm{mol}^{-1}$ & $R_{\mathrm{h}-\mathrm{D}}, \mathrm{nm}$ & {$[\eta], \mathrm{cm}^{3} \cdot \mathrm{g}^{-1}$} & $\begin{array}{c}A_{0} \times 10^{10} \\
\mathrm{erg} \cdot \mathrm{K}^{-1} \mathbf{m o l}^{-1 / 3}\end{array}$ & CMC, wt $\%$ \\
\hline \multicolumn{6}{|c|}{ polyE7P3 } \\
\hline water & $33,000 \pm 3000$ & $3.2 \pm 0.3$ & $12 \pm 0.6$ & 3.9 & $3.4 \cdot 10^{-4}$ \\
\hline chloroform & $20,000 \pm 2000$ & $2.1 \pm 0.2$ & $8.0 \pm 0.4$ & 4.1 & \\
\hline THF & $10,000 \pm 1000,11,000 *$ & $2.1 \pm 0.2$ & $6.3 \pm 0.3$ & 3.0 & \\
\hline acetonitrile & $12,000 \pm 1200$ & $2.1 \pm 0.2$ & $6.0 \pm 0.3$ & 2.9 & \\
\hline \multicolumn{6}{|c|}{ polyE7P5 } \\
\hline water & $180,000 \pm 1800$ & $4.2 \pm 0.3$ & $15 \pm 0.6$ & 5.2 & $3.2 \cdot 10^{-4}$ \\
\hline chloroform & $50,000 \pm 4000$ & $3.9 \pm 0.3$ & $9.9 \pm 0.5$ & 3.9 & \\
\hline THF & $15,000 \pm 1500,14,000 *$ & $2.9 \pm 0.3$ & $8.0 \pm 0.4$ & 2.7 & \\
\hline acetonitrile & $15,000 \pm 1500$ & $2.9 \pm 0.3$ & $8.0 \pm 0.4$ & 2.7 & \\
\hline \multicolumn{6}{|c|}{ polyE7P10 } \\
\hline water & $77,000 \pm 7000$ & $4.3 \pm 0.4$ & $19 \pm 0.8$ & 4.2 & $2.7 \cdot 10^{-4}$ \\
\hline chloroform & $87,000 \pm 8000$ & $4.2 \pm 0.4$ & $12 \pm 0.6$ & 3.9 & \\
\hline THF & $20,000 \pm 200015,000 *$ & $3.2 \pm 0.3$ & $11 \pm 0.5$ & 3.0 & \\
\hline acetonitrile & $17,000 \pm 1700$ & $3.0 \pm 0.3$ & $11 \pm 0.5$ & 2.8 & \\
\hline
\end{tabular}

Table 1. The molar masses, hydrodynamic characteristics, and CMC of polyOEGeOPGpMAs.

* These values of $M_{\mathrm{w}}$ were obtained by GPC. 
The viscosimetry experiments were carried out on the Ostwald-type Cannon-Manning capillary viscometer (Cannon Instrument Company Inc., State College, PA, USA). The efflux time of the solvent was $104.5 \mathrm{~s}$. The dependencies of the reduced viscosity $\eta_{\mathrm{sp}} / c$ on the concentration were analyzed using the equation of Huggins:

$$
\eta_{\mathrm{sp}} / c=[\eta]+k_{\mathrm{H}}[\eta]^{2} c
$$

where [ $\eta$ ] is the intrinsic viscosity and $k_{\mathrm{H}}$ is the Huggins constant.

The solutions, solvent, and calibration liquid were filtered into cells that were ensured to be dust-free previously by benzene. Millipore filters (Millipore Corp., Billerica, MA, USA) with a PTFE membrane with the pore size of $0.20 \mu \mathrm{m}$ were used. The described experiments were carried out at $21^{\circ} \mathrm{C}$. Before the experiments, the scattering cells were rinsed with benzene, evacuated for $15 \mathrm{~min}$, and filled with dust-free air. The solutions were prepared at room temperature. All solutions were stored for at least $12 \mathrm{~h}$ prior to measurements in order to ensure a complete equilibration.

The critical micelle concentrations (CMC) of copolymers were determined by fluorimetry using pyrene as a fluorescent probe $[35,36]$. The aqueous solutions of polymers with 10 different concentrations in the range of $1 \cdot 10^{-6} \div 0.5 \mathrm{mg} / \mathrm{mL}$ were prepared by dissolving the polymers in aqueous pyrene solutions $\left(6 \cdot 10^{-7} \mathrm{M}\right)$. The resulting mixtures were then sonicated for $5 \mathrm{~min}$ and allowed to equilibrate for $24 \mathrm{~h}$ at room temperature before measurements. Steady-state fluorescence spectra were recorded on a Shimadzu RF-6000 spectrofluorimeter (Shimadzu, Kyoto, Japan) under the following conditions: the excitation slit width was $3 \mathrm{~nm}$, the emission slit width was $3 \mathrm{~nm}$, the scanning speed was $200 \mathrm{~nm} / \mathrm{min}$, the excitation wavelength was $335.0 \mathrm{~nm}$, the emission wavelength was $350.0-500.0 \mathrm{~nm}$, and the temperature was $25^{\circ} \mathrm{C}$. The ratio between the intensities $\left(I_{1} / I_{3}\right)$ of the first $\left(I_{1}, 373 \mathrm{~nm}\right)$ and the third $\left(I_{3}, 384 \mathrm{~nm}\right)$ vibronic bands of pyrene emission were plotted against the polymer concentration (Figure 3). Critical micelle concentrations were determined as a concentration corresponding to the inflection point at which $I_{1} / I_{3}$ started to decrease.

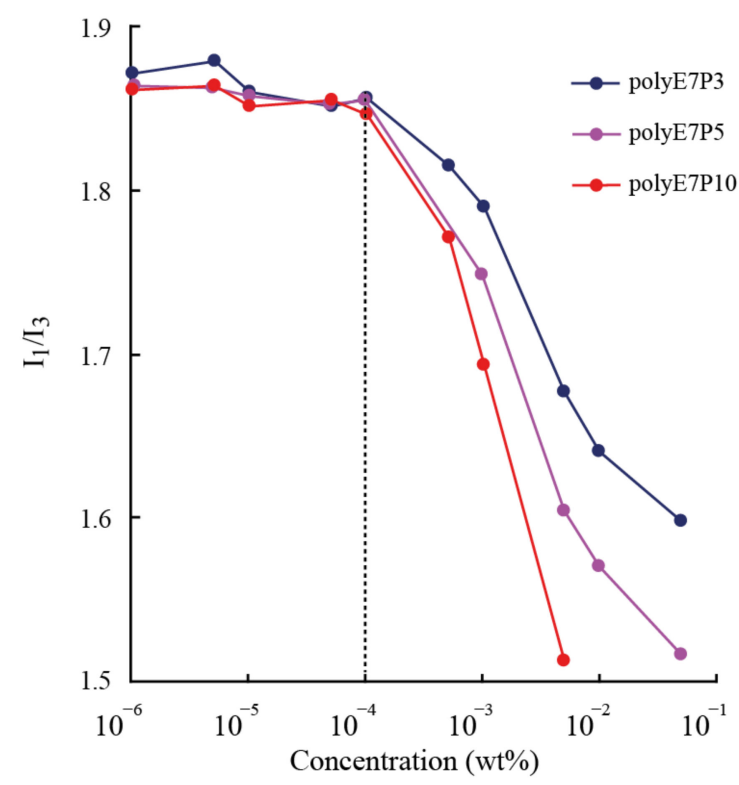

Figure 3. $I_{1} / I_{3}$ ratio of the vibronic band intensities of pyrene as a function of a polymer concentration.

\subsection{Investigation of the Self-Assembly of PolyOEGeOPGPMA in Water Solutions}

The processes of the self-organization of polyOEGeOPGpMA in aqueous solutions were investigated by the methods of s SLS, DLS, and turbidimetry using the Photocor Complex (Photocor Instruments Inc., Moscow, Russia) described above, which was also equipped with the Photocor-PD detection device for measuring the transmitted light in- 
tensity. The experimental procedure was described in detail previously [37]. The polymer concentration was equal to $0.005 \mathrm{~g} \cdot \mathrm{cm}^{-3}$ for all copolymer samples. The solution temperature $T$ was changed discretely with the step ranging from 1.0 to $5.0^{\circ} \mathrm{C}$. The temperature was regulated with the precision of $0.1^{\circ} \mathrm{C}$. The $T$ values changed in a range from 15 to $79^{\circ} \mathrm{C}$. After a given temperature was achieved, all of the experimental characteristics began to change in time and reached constant values in time $t_{\text {eq. }}$. At steady-state conditions, i.e., when the solution characteristics do not depend on time, the intensity $I$ of scattered light, optical transmition $I^{*}$, hydrodynamic radii $R_{\mathrm{h}}$ of the scattering species, and their contribution $S_{\mathrm{i}}$ to the integral scattering intensity were determined. $S_{\mathrm{i}}$ was estimated using the values of the areas under the curved line of the corresponding $R_{\mathrm{h}}$ distribution peak. These measurements were performed at a scattering angle range from $45^{\circ}$ to $135^{\circ}$ to prove the diffusion nature of the modes. To maintain the linearity of the instrument with respect to $I$, the amount of fixed light scattering was attenuated by filters and by reducing the laser power so that the measured value of I did not exceed $1.2 \mathrm{MHz}$.

\section{Result and Discussion}

\subsection{Molar-Masses and Hydrodynamic Characteristics}

For all samples of polyOEGeOPGpMA, the molar masses, hydrodynamic radii of the macromolecules, and intrinsic viscosities determined by the static light scattering method (SLS) (Photocor Instruments Inc, Moscow, Russia) and Gel permeation chromatography (GPC) (Chromos LC-301, Chromos Engineering Co. Ltd., Dzerzhinsk, Russia) instrument with isocratic pump, refractometric detector and two exclusive columns Phenogel 5u 50A (Phenomenex, Torrance, CA, USA) in tetrahydrofuran (THF) and acetonitrile solutions coincide within the experimental error (Table 1). Using the obtained $M_{\mathrm{W}}$ values, it is easy to calculate the polymerization degree $N_{\mathrm{b}}$ of the backbone of the copolymers according to the equation

$$
N_{\mathrm{b}}=M_{\mathrm{w}} / M_{0-\mathrm{cp}}
$$

where $M_{0-\mathrm{cp}}$ is molar masses repeating the units of OEGeOPGpMA: $M_{0-\mathrm{cp}}=582 \mathrm{~g} \cdot \mathrm{mol}^{-1}$ for polyE7P3, $M_{0-\text { cp }}=688 \mathrm{~g} \cdot \mathrm{mol}^{-1}$ for polyE7P5, and $M_{0-\mathrm{cp}}=988 \mathrm{~g} \cdot \mathrm{mol}^{-1}$ for polyE7P10. The $N_{\mathrm{b}}$ values are listed in Table 2. Table 2 also presents the average values of the length $L_{\mathrm{b}}=N_{\mathrm{b}}$ $\lambda_{0-\mathrm{b}}$ of backbone. Length $L_{\mathrm{b}}$ was calculated under the assumption that all valence bonds have the same length of $0.14 \mathrm{~nm}$. The valence angles are tetrahedral and, consequently, the length of the repeating unit of the main chain $\lambda_{0-\mathrm{b}}=0.25 \mathrm{~nm}$. The lengths $L_{\mathrm{sc}}$ of the side chains were determined in the same way (Table 2).

Table 2. Structural characteristics of polyOEGeOPGpMA.

\begin{tabular}{ccccc}
\hline Sample & $\boldsymbol{M}_{\mathbf{w}}, \mathbf{g} \cdot \mathbf{m o l}^{-\mathbf{1}}$ & $\boldsymbol{N}_{\mathbf{b}}$ & $\boldsymbol{L}_{\mathbf{b}}, \mathbf{n m}$ & $\boldsymbol{L}_{\mathbf{s c}}, \mathbf{n m}$ \\
\hline polyE7P3 & $\sim 11,000$ & 19 & 4.8 & 4.2 \\
polyE7P5 & 15,000 & 22 & 5.5 & 4.9 \\
polyE7P10 & 17,000 & 18 & 4.6 & 6.8 \\
\hline
\end{tabular}

It is clearly seen that, for investigated samples, the lengths of the main and side chains are close. Back in 1986, V. Tsvetkov suggested that comb-like macromolecules with such a ratio of length components, even in a good solvent, should have a shape similar to a star-shaped macromolecule [11]. Simplified schemes of the molecules of the studied samples are shown in Figure 4. It is convenient to model such structures with an ellipsoid of revolution [11]. Taking into account the $L_{\mathrm{b}}$ and $L_{\mathrm{sc}}$ values, it can be assumed with great confidence that the ratio of the length and short axes of the modeling ellipsoids for the studied polymers will not differ very much from unity. 


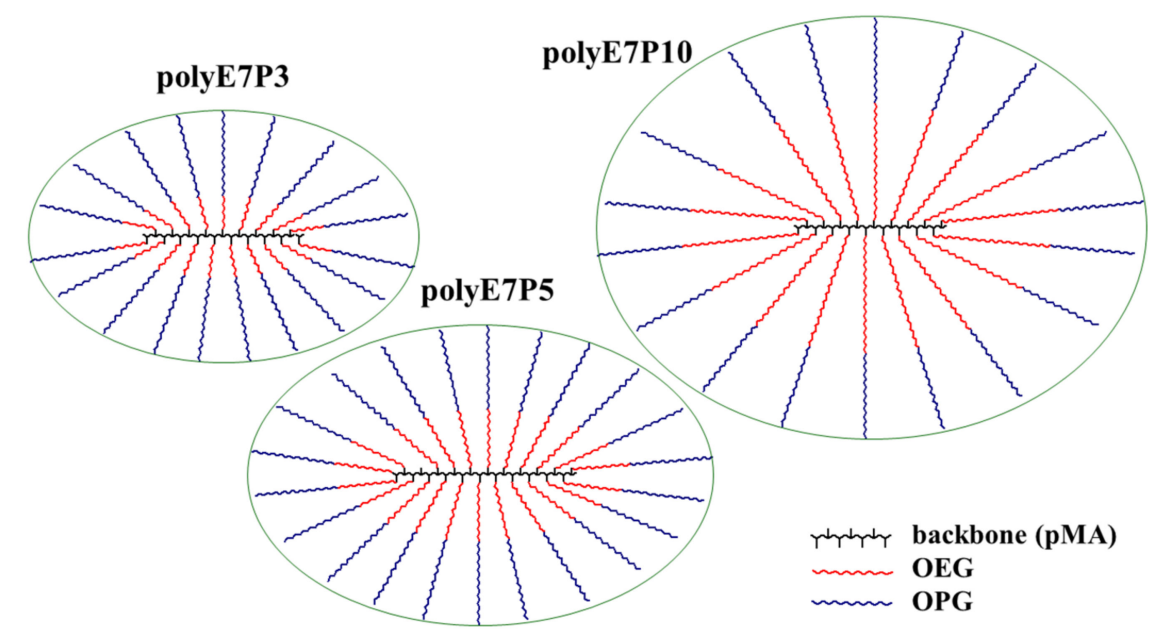

Figure 4. Simplified schemes of the molecules of polyOEGeOPGpMA.

The fact that the shape of polyOEGeOPGpMA molecules resembles a star-shaped macromolecule is evidenced by the obtained low values of intrinsic viscosity (Table 1). Such low values are typical for multi-armed polymer stars [38,39]. They indicate the compact size and symmetrical shape of macromolecules. The compact size and increased intermolecular density are confirmed by the low values of the hydrodynamic radii $R_{\mathrm{h}-\mathrm{D}}$ determined in acetonitrile and THF (Table 1). In addition, for the studied copolymers, low values of the hydrodynamic variant $A_{0}$ were obtained (Table 1). $A_{0}$ were calculated using the experimental values of the values of $M_{\mathrm{w}}[\eta]$ and $D_{0}$ by the formula $[11,40,41]$

$$
A_{0}=\eta_{0} D_{0}\left(\frac{M[\eta]}{100}\right)^{1 / 3} / T_{\mathrm{a}}
$$

where $T_{\mathrm{a}}$ is absolute temperature. As known, the average theoretical and experimental values of the hydrodynamic invariant for flexible-chain polymers is $A_{0}=(3.2 \pm$ $0.2) \cdot 10^{-10} \mathrm{erg} \cdot \mathrm{K}^{-1} \mathrm{~mol}^{-1 / 3}[11,40,41]$, and the theoretical estimate for the impermeable solid sphere gives $A_{0}=2.88 \cdot 10^{-10} \mathrm{erg} \cdot \mathrm{K}^{-1} \mathrm{~mol}^{-1 / 3}$. For multi-armed polymer stars, a decrease in the experimental values of $A_{0}$ was observed in comparison with $A_{0}$ for linear polymers. For example, for six-arm poly (2-alkyl-2-oxazolines) $A_{0}=2.8 \cdot 10^{-10} \mathrm{erg} \cdot \mathrm{K}^{-1} \mathrm{~mol}^{-1 / 3}$ [42]. The $A_{0}$ value for star-shaped polymers decreases with an increase in the number of arms and a decrease in their length.

Thus, the performed analysis suggests that, in tetrahydrofuran and acetonitrile, the conformation of the studied copolymers is similar to the conformation of a polymer star, which has an elongated core (main chain) and whose arms are side chains. The number of the latter coincides with the polymerization degree of the backbone.

On passage from tetrahydrofuran and acetonitrile to chloroform and water, a change in the hydrodynamic characteristics was observed (Table 1). The intrinsic viscosities [ $\eta]$ increased most strongly. The values of the hydrodynamic radius $R_{\mathrm{h}-\mathrm{D}}$ and hydrodynamic invariant $A_{0}$ behaved in exactly the same way. Their changes were not very great, but it can be traced reliably. It can be assumed that the aggregates were formed in these solvents, which is reflected in the experimental values of the molar masses (Table 1).

Aggregate formation is confirmed by fluorimetry. Table 1 presents the critical micelle concentrations of brushes in water. It was found that polymers have $\mathrm{CMC}$ values of about $3 \cdot 10^{-4}$ wt.\%. Considering the low CMC values, it is obvious that the sizes determined by DLS in water are the sizes of polymer micelles. Furthermore, given the similar molar masses of the samples, one can observe a clear tendency for the CMC to decrease (from $3.35 \cdot 10^{-4}$ to $2.70 \cdot 10^{-4}$ ) as the length of the hydrophobic blocks in the side chains increases. 


\subsection{Properties of the Aqueous Solutions of PolyOEGeOPGpMA}

At room temperature, the dynamic light scattering method recorded the existence of only one mode in aqueous solutions of the investigated samples. As well as for solutions of polyOEGeOPGpMA in acetonitrile and THF, the hydrodynamic radius $R_{\mathrm{h}-\mathrm{m}}=R_{\mathrm{h}-\mathrm{D}}$ of particles corresponding to this mode was determined by the extrapolation to zero concentration (Figure S3). The values of radius $R_{\mathrm{h}-\mathrm{m}}$ depended on the length of the hydrophobic block in the side chains. The highest aggregate sizes were obtained for polyE7P10 $\left(R_{\mathrm{h}-\mathrm{m}}=4.3 \mathrm{~nm}\right)$, the smallest for polyE7P3 $\left(R_{\mathrm{h}-\mathrm{m}}=3.2 \mathrm{~nm}\right)$, and $R_{\mathrm{h}-\mathrm{m}}=4.2 \mathrm{~nm}$ for polyE7P5.

The phase transition was detected in polyOEGeOPGpMA solutions upon heating by light scattering and turbidimetry methods. Figure 5 shows the temperature dependences of the relative optical transmission $I^{*} / I^{*}{ }_{21}$ for the studied solutions. The observed behavior is typical for thermoresponsive polymers [43-48]. The temperatures of the onset $T_{1}$ and the finishing $T_{2}$ of the phase separation were defined as the beginning of the decrease in $I^{*} / I^{*}{ }_{21}$ and as reaching its minimum value, respectively. With the elongation of the hydrophobic component in the side chains of polyOEGeOPGpMA, the dependences $I^{*} / I^{*}{ }_{21}(T)$ shift to the region of low temperatures, i.e., the phase separation temperatures $T_{1}$ and $T_{2}$ decrease with increasing OPG content.

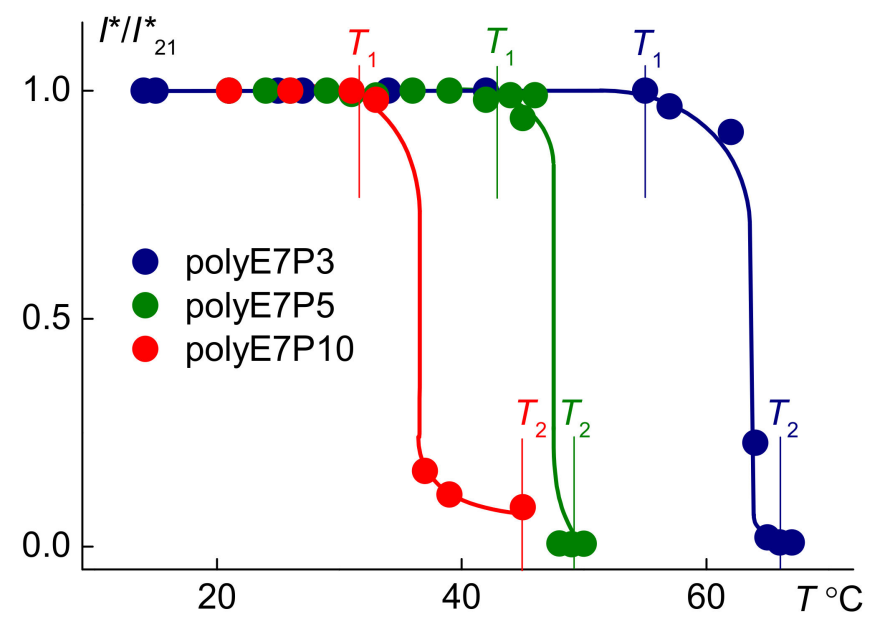

Figure 5. Temperature dependences of the relative optical transmission $I^{*} / I^{*} 21$ for the aqueous solutions of polyOEGeOPGPMA at concentration $c \approx 0.0050 \mathrm{~g} \cdot \mathrm{cm}^{-3} \cdot I^{*}{ }_{21}$ is optical transmission at $21{ }^{\circ} \mathrm{C}$.

At $T<T_{1}$, the light scattering intensity $I$ did not change upon heating (Figure 6). This is explained by the independence of the radii of scattering objects $R_{\mathrm{h}-\mathrm{m}}$ on temperature (Figure 7 and Figure S6 (Supplementary Materials)). Within the phase separation interval, the strong increase in intensity I was observed for all solutions. Such behavior was caused by the change in the composition of the scattering species and their dimensions. Near the temperature of onset $T_{1}$ of the phase separation, the new aggregates with hydrodynamic radii $R_{\mathrm{h}-\mathrm{s}}$ appeared in the solutions. The main reason for the formation of these supramolecular structures is the dehydration of the OPG block. For all samples, the radius increased upon heating and reached the maximal value at temperature $T_{2}$, at which point the intensity of scattered light became maximum. Near $T_{1}$, micelle-like aggregates with a radius of $R_{\mathrm{h}-\mathrm{m}}$ cease to be detected by the dynamic light scattering since they formed large aggregates with a radius $R_{\mathrm{h}-\mathrm{s}}$. 


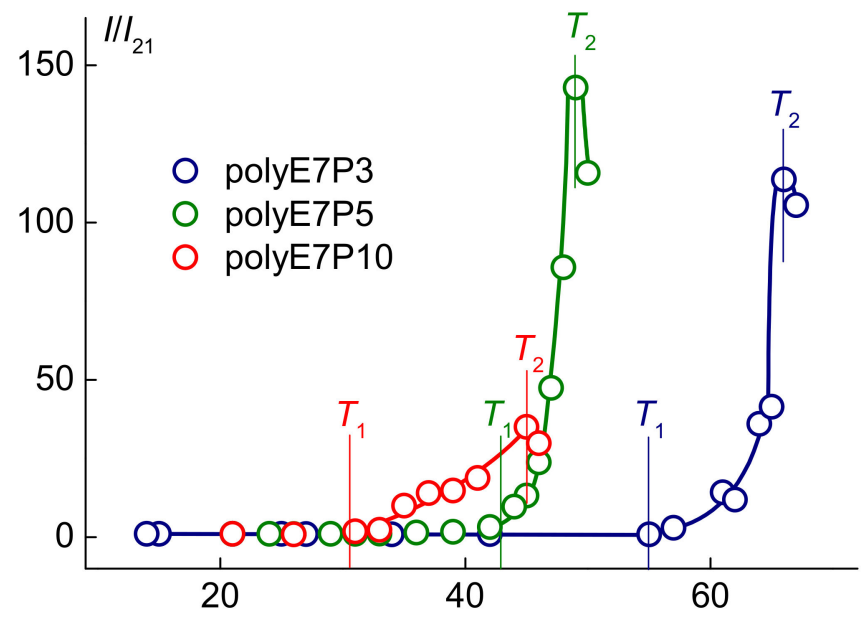

Figure 6. Temperature dependences of the relative light scattering intensity $I / I_{21}$ for the aqueous solutions of polyOEGeOPGpMA at concentration $c \approx 0.0050 \mathrm{~g} \cdot \mathrm{cm}^{-3} \cdot I_{21}$ is light scattering intensity at $21^{\circ} \mathrm{C}$.

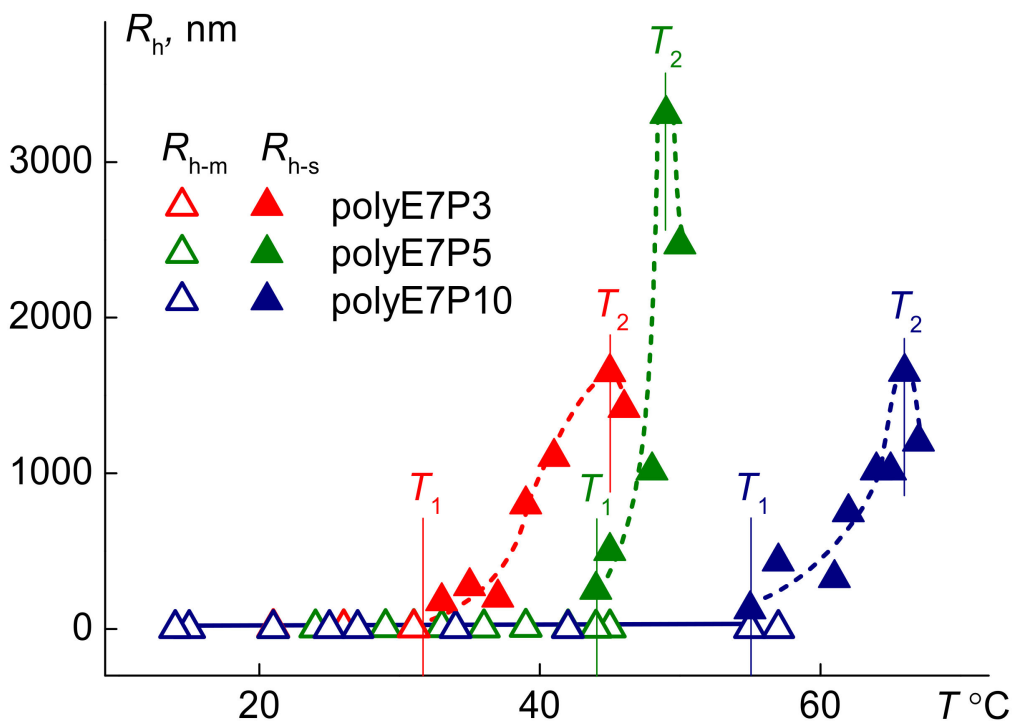

Figure 7. Temperature dependences of the hydrodynamic radii $R_{\mathrm{h}-\mathrm{m}}$ and $R_{\mathrm{h}-\mathrm{s}}$ for the aqueous solutions of polyOEGeOPGpMA at concentration $c \approx 0.0050 \mathrm{~g} \cdot \mathrm{cm}^{-3} \cdot I_{21}$ is light scattering intensity at $21^{\circ} \mathrm{C}$.

At $T>T_{2}$, both $I$ and $R_{\mathrm{h}-\mathrm{m}}$ decreased with temperature. This fact can reflect the compaction of the copolymer molecules and aggregates due to the dehydration of side chains. However, the solutions were turbid and the light scattering was not classical (multiple scattering) [49,50].

\section{Conclusions}

Molecular brushes polyOEGeOPGpMA were investigated by the methods of molecular hydrodynamics and optics in dilute solutions in acetonitrile, THF, chloroform, and water. The polymerization degree of the studied samples was about 20 . The copolymers are molecularly dispersedly dissolved in THF and acetonitrile. In these solvents, OEGeOPGpMA are characterized by a high intramolecular density, and the shape of their molecules resembles a star-shaped macromolecule. The core of this "star" is the extended backbone of the grafted copolymer, and the arms are the side chains. In chloroform and water, the formation of small micelle-like aggregates was observed. CMC in water decreased with the lengthening of the hydrophobic OPG block. 
In aqueous solutions, the studied copolymers demonstrated thermoresponsibility. The phase separation temperatures decreased with an increase in the content of the OPG block in the side chains. For all studied copolymers, phase separation occurred with the formation of large micron-sized aggregates.

Supplementary Materials: The following are available online at https:/ /www.mdpi.com/article/ 10.3390/polym13162715/s1, Figure S1: 1H NMR spectra of the monomers in DMSO-D6, Figure S2: GPC traces of the copolymers investigated, Figure S3: Concentration dependences of radius Rh-D for OEGeOPGpMA in acetonitrile (right) and water (left), Figure S4: Debye plots for OEGeOPGpMA in acetonitrile and water.

Author Contributions: Conceptualization, M.S., D.K. and A.F.; formal analysis, M.S. and A.F.; investigation, M.N.; project administration, M.S. and O.K.; visualization, D.K.; writing—original draft, M.S. and A.F.; writing - review and editing, D.K., O.K. and A.F. All authors have read and agreed to the published version of the manuscript.

Funding: This study was financially supported by the Russian Science Foundation (project № 20-13-00161).

Institutional Review Board Statement: Not applicable.

Informed Consent Statement: Not applicable.

Data Availability Statement: The data presented in this study are available upon request from the corresponding author.

Conflicts of Interest: The authors declare no conflict of interest.

\section{Abbreviations}

$\rho_{0} \quad$ density

$\eta_{0} \quad$ dynamic viscosity

$n_{0} \quad$ refractive index

$R_{\mathrm{h}-\mathrm{D}} \quad$ hydrodynamic radii of macromolecule

$R_{\mathrm{h}-\mathrm{m}} \quad$ hydrodynamic radius of micelle

$D_{0} \quad$ translation diffusion coefficient

$T$ absolute temperature

$T$ temperature

$T_{1} \quad$ the onset of phase separation

$T_{2}$ the finishing of phase separation

$M_{\mathrm{w}} \quad$ molar mass

$M_{0} \quad$ molar mass repeating units

$A_{2} \quad$ second virial coefficient

$I_{90}$ the excessive intensity of light scattered at an angle of 90

$d n / d c \quad$ refractive index increment

[n] intrisic viscosity

$A_{0} \quad$ hydrodynamic invariant

$\lambda_{0} \quad$ wavelength

$L_{\mathrm{b}} \quad$ length of backbone

$L_{\mathrm{sc}} \quad$ lengths of the side chains

$N_{\mathrm{b}} \quad$ polymerization degree

$I^{*} / I^{*} 21$ relative optical transmission

$I / I_{21} \quad$ relative light scattering intensity

$I^{*} \quad$ intensity of optical transmission

I light scattering intensity

$I_{21} \quad$ light scattering intensity at $21^{\circ} \mathrm{C}$

$S_{\mathrm{i}} \quad$ contribution to the integral scattering intensity

$\mathrm{g} \cdot \mathrm{cm}^{-3}$
$\mathrm{cP}$
-
$\mathrm{nm}$
$\mathrm{nm}$
$\mathrm{cm}^{2} \times \mathrm{g}^{-1}$
${ }^{\circ} \mathrm{K}$
${ }^{\circ} \mathrm{C}$
${ }^{\circ} \mathrm{C}$
${ }^{\circ} \mathrm{C}$
$\mathrm{g} \cdot \mathrm{mol}^{-1}$
$\mathrm{~g} \cdot \mathrm{mol}^{-1}$
$\mathrm{~cm}^{3} \cdot \mathrm{mol}^{\circ} \mathrm{g}^{-2}$
$\mathrm{~Hz}$
$\mathrm{~cm} \cdot \mathrm{g}^{-1}$
$\mathrm{~cm} \cdot \mathrm{g}^{-1}$
$\mathrm{erg} \cdot \mathrm{K}^{-1} \mathrm{~mol}^{-1 / 3}$
$\mathrm{~nm}$
$\mathrm{~nm}$
$\mathrm{~nm}$
-
-
-
$\mathrm{Hz}$
$\mathrm{Hz}$
$\mathrm{Hz}$
$\%$
$\%$




\section{References}

1. Zhang, M.; Muller, A.H.E. Cylindrical Polymer Brushes. J. Polym. Sci. Part A Polym. Chem. 2005, 43, 3461-3469. [CrossRef]

2. Xie, G.; Martinez, M.R.; Olszewski, M.; Sheiko, S.S.; Matyjaszewski, K. Molecular bottlebrushes as novel materials. Biomacromolecules 2019, 20, 27-54. [CrossRef]

3. Ivanov, I.V.; Meleshko, T.K.; Kashina, A.V.; Yakimansky, A.V. Amphiphilic multicomponent molecular brushes. Russ. Chem. Rev. 2019, 88, 1248-1290. [CrossRef]

4. Verduzco, R.; Li, X.; Pesek, S.L.; Stein, G.E. Structure, function, self-assembly, and applications of bottlebrush copolymers. Chem. Soc. Rev. 2015, 44, 2405-2420. [CrossRef]

5. Li, H.; Liu, H.; Nie, T.; Chen, Y.; Wang, Z.; Huang, H.; Liu, L.; Chen, Y. Molecular bottlebrush as a unimolecular vehicle with tunable shape for photothermal cancer therapy. Biomaterials 2018, 178, 620-629. [CrossRef]

6. Müllner, M.; Dodds, S.J.; Nguyen, T.-H.; Senyschyn, D.; Porter, C.J.H.; Boyd, B.J.; Caruso, F. Size and rigidity of cylindrical polymer brushes dictate long circulating properties In Vivo. ACS Nano 2015, 9, 1294-1304. [CrossRef] [PubMed]

7. Müllner, M. Molecular polymer brushes in nanomedicine. Macromol. Chem. Phys. 2016, 217, 2209-2222. [CrossRef]

8. Huang, K.; Canterbury, D.P.; Rzayev, J. Organosoluble polypyrrole nanotubes from core-shell bottlebrush copolymers. Chem. Commun. 2010, 46, 6326-6328. [CrossRef] [PubMed]

9. Müllner, M.; Yuan, J.; Weiss, S.; Walther, A.; Förtsch, M.; Drechsler, M.; Müller, A.H.E. Water-soluble organo-silica hybrid nanotubes templated by cylindrical polymer brushes. J. Am. Chem. Soc. 2010, 132, 16587-16592. [CrossRef]

10. Müllner, M.; Lunkenbein, T.; Schieder, M.; Gröschel, A.H.; Miyajima, N.; Förtsch, M.; Breu, J.; Caruso, F.; Müller, A.H.E. Templatedirected mild synthesis of anatase hybrid nanotubes within cylindrical core-shell-corona polymer brushes. Macromolecules 2012, 45, 6981-6988. [CrossRef]

11. Tsvetkov, V.N. Rigid-Chain Polymers Hydrodynamic and Optical Properties in Solution, 1st ed.; Plenum Press: New York, NY, USA, 1989; pp. 1-512.

12. Simonova, M.; Ivanov, I.; Meleshko, T.; Kopyshev, A.; Santer, S.; Yakimansky, A.; Filippov, A. Self-Assembly of Molecular Brushes with Polyimide Backbone and Amphiphilic Block-Copolymer Side Chains in Selective Solvents. Polymers 2020, 12, 2922. [CrossRef]

13. Rodchenko, S.; Amirova, A.; Kurlykin, M.; Tenkovtsev, A.; Milenin, S.; Filippov, A. Amphiphilic Molecular Brushes with Regular Polydimethylsiloxane Backbone and Poly-2-isopropyl2-oxazoline Side Chains. 2. Self-Organization in Aqueous Solutions on Heating. Polymers 2021, 13, 31.

14. Filippov, A.P.; Belyaeva, E.V.; Krasova, A.S.; Simonova, M.A.; Meleshko, T.K.; Ilgach, D.M.; Bogorad, N.N.; Yakimansky, A.V.; Larin, S.V.; Darinskii, A.A. Conformations of Molecular Brushes Based on Polyimide and Poly(methyl methacrylate) in Selective Solvents: Experiment and Computer Simulation. Polym. Sci. Ser. A 2014, 56, 393-404. [CrossRef]

15. Filippov, A.P.; Belyaeva, E.V.; Krasova, A.S.; Simonova, M.A.; Tarabukina, E.B.; Meleshko, T.K.; Ilgach, D.M.; Bogorad, N.N.; Yakimansky, A.V. Synthesis and investigation of the solution behavior of graft block-copolymers of polyimide and poly(methyl methacrylate. Polym. Sci. Ser. A. 2014, 56, 1-9. [CrossRef]

16. Meleshko, T.K.; Ivanov, I.V.; Kashina, A.V.; Bogorad, N.N.; Simonova, M.A.; Zakharova, N.V.; Filippov, A.P.; Yakimansky, A.V. Diphilic macromolecular brushes with a polyimide backbone and poly(methacrylic acid) blocks in side chains. Polym. Sci. Ser. B 2018, 60, 35-50. [CrossRef]

17. Zakharova, N.V.; Simonova, M.A.; Zelinskii, S.N.; Annenkov, V.V.; Filippov, A.P. Synthesis, molecular characteristics, and stimulus-sensitivity of graft copolymer of chitosan and poly (N, N-diethylacrylamide). J. Mol. Liquids 2019, 292, 111355. [CrossRef]

18. Kudryavtseva, A.A.; Kurlykin, M.P.; Tarabukina, E.B.; Tenkovtsev, A.V.; Filippov, A.P. Behavior of thermosensitive graft copolymer with aromatic polyester backbone and poly-2-ethyl-2-oxazoline side chains in aqueous solutions. Int. J. Polym. Anal. Charact. 2017, 22, 526-533. [CrossRef]

19. Vancoillie, G.; Frank, D.; Hoogenboom, R. Thermoresponsive poly(oligo ethyleneglycol acrylates). Prog. Polym. Sci. 2014, 39, 1074-1095. [CrossRef]

20. Zhang, X.J.; Dai, Y. Recent development of brush polymers via polymerization of poly(ethylene glycol)-based macromonomers. Polym. Chem. 2019, 10, 2212-2222. [CrossRef]

21. Badi, N. Non-linear PEG-based thermoresponsive polymer systems. Prog. Polym. Sci. 2017, 66, 54-79. [CrossRef]

22. Liu, M.; Leroux, J.C.; Gauthier, M.A. Conformation-function relationships for the combshaped polymer pOEGMA. Prog. Polym. Sci. 2015, 48, 111-121. [CrossRef]

23. Lutz, J.F.; Hoth, A.; Schade, K. Design of Oligo(ethylene glycol)-Based Thermoresponsive Polymers: An Optimization Study. Des. Monomers Polym. 2009, 12, 343-353. [CrossRef]

24. Lutz, J.F. Polymerization of oligo(ethylene glycol) (meth)acrylates: Toward new generations of smart biocompatible materials. J. Polym. Sci. Part A Polym. Chem. 2008, 46, 3459-3470. [CrossRef]

25. Neugebauer, D. Graft copolymers with poly(ethylene oxide) Segments. Polym. Int. 2007, 56, 1469-1498. [CrossRef]

26. Zhou, T.; Wu, W.; Zhou, S. Engineering oligo(ethylene glycol)-based thermosensitive microgels for drug delivery applications. Polymer 2010, 51, 3926-3933. [CrossRef]

27. Wang, Y.; Yuan, Z.C.; Chen, D.J. Thermo- and pH-sensitive behavior of hydrogels based on oligo (ethylene glycol) methacrylates and acrylic acid. J. Mat. Sci. 2012, 47, 1280-1288. [CrossRef] 
28. Bodratti, A.M.; Alexandridis, P. Formulation of Poloxamers for Drug Delivery. J. Funct. Biomater. 2018, 9, 11. [CrossRef]

29. Orekhov, D.V.; Kazantsev, O.A.; Sivokhin, A.P.; Savinova, M.V. Features of the acidcatalyzed hydrolysis of mono- and poly(ethylene glycol) methacrylates. Europ. Polym. J. 2018, 100, 18-24. [CrossRef]

30. Shibata, M.; Matsumoto, M.; Hirai, Y.; Takenaka, M.; Sawamoto, M.; Terashima, T. Intramolecular Folding or Intermolecular Self-Assembly of Amphiphilic Random Copolymers: On-Demand Control by Pendant Design. Macromolecules 2018, 51, $3738-3745$. [CrossRef]

31. Matsumoto, M.; Takenaka, M.; Sawamoto, M.; Terashima, T. Self-assembly of amphiphilic block pendant polymers as microphase separation materials and folded flower micelles. Polym Chem. 2019, 10, 4954-4961. [CrossRef]

32. Sivokhin, A.P.; Orekhov, D.V.; Kazantsev, O.A.; Gubanova, O.V.; Kamorin, D.M.; Zarubina, I.S.; Bolshakova, E.A.; Zaitsev, S.D. Amphiphilic thermoresponsive copolymer bottlebrushes: Synthesis, characterization and study of their self-assembly into flower-like micelles. Polym. J. 2021, 53, 655-665. [CrossRef]

33. Paris, R.; Quijada-Garrido, I. Synthesis and aggregation properties in water solution of comblike methacrylic polymers with oligo(propylene glycol)-block-oligo(ethylene glycol) as side chains. J. Polym. Sci. Part A Polym. Chem. 2011, 49, 1928-1932. [CrossRef]

34. Kazantsev, O.A.; Bolshakova, E.A.; Orekhov, D.V.; Simagin, A.S.; Kamorin, D.M.; Sivokhin, A.P. Synthesis and thermoresponsive properties of polymethacrylate molecular brushes with oligo(ethylene glycol)-block-oligo(propylene glycol) side chains. Polym. Bulletin. 2021, in press.

35. Zhao, C.L.; Winnik, M.A.; Riess, G.; Croucher, M.D. Fluorescence probe techniques used to study micelle formation in watersoluble block copolymers. Langmuir 1990, 6, 514-516. [CrossRef]

36. Naksuriya, O.; Shi, Y.; van Nostrum, C.F.; Anuchapreeda, S.; Hennink, W.E.; Okonogi, S. HPMA-based polymeric micelles for curcumin solubilization and inhibition of cancer cell growth. Europ. J. Pharm. Biopharm. 2015, 94, 501-512. [CrossRef] [PubMed]

37. Filippov, A.; Tarabukina, E.; Simonova, M.; Kirila, T.; Fundueanu, G.; Harabagiu, V.; Constantin, M.; Popescu, I. Synthesis and Investigation of double stimuli-responsive behavior of $\mathrm{N}$-Isopropylacrylamide and maleic acid copolymer in solutions. $J$. Macromol. Sci. Part B 2015, 54, 1105-1121. [CrossRef]

38. Simonova, M.A.; Tarasova, E.V.; Dudkina, M.M.; Tenkovtsev, A.V.; Filippov, A.P. Synthesis and hydrodynamic and conformation properties of star-shaped polystyrene with calix[8]arene core. Int. J. Polym. Anal. Charact. 2019, 24, 87-95. [CrossRef]

39. Burchard, W. Solution properties of branched macromolecules. Adv. Polym. Sci. 1999, 143, 113-194.

40. Tsvetkov, V.N.; Lavrenko, P.N.; Bushin, S.V. A hydrodynamic invariant of polymeric molecules. Russ. Chem. Rev. 1982, 51, 975-993. [CrossRef]

41. Tsvetkov, V.N.; Lavrenko, P.N.; Bushin, S.V. Hydrodynamic invariant of polymer molecules. J. Polym. Sci. 1984, 22, 3447-3486. [CrossRef]

42. Kirila, T.; Smirnova, A.; Razina, A.; Tenkovtsev, A.; Filippov, A. Synthesis and conformational characteristics of thermosensitive star-shaped six-arm polypeptoids. Polymers 2020, 12, 800. [CrossRef]

43. Simonova, M.A.; Khayrullin, A.R.; Tyurina, V.O.; Filippov, A.P.; Sadikov, A.Y.; Kamorin, D.M.; Kamorina, S.I. Self-Organization Processes in Poly (N-[2-(diethylamino) ethyl] acrylamide) Buffer Solutions with Change in Concentration and $\mathrm{pH}$ of a Medium. Polym. Sci. 2020, 62, 24-31. [CrossRef]

44. Simonova, M.A.; Khayrullin, A.R.; Turina, V.O.; Kamorina, S.I.; Kamorin, D.M.; Sadikov, A.Y.; Filippov, A.P. Self-organization in water solutions of thermosensitive linear copolymers based on $\mathrm{N}$-(dimethylamino)ethyl methacrylate. Int. J. Polym. Anal. Charact. 2019, 24, 630-642. [CrossRef]

45. Wei, M.; Gao, Y.; Li, X.; Serpe, M.J. Stimuli-responsive polymers and their applications. Polym. Chem. 2017, 8, 127-143. [CrossRef]

46. Dimitrov, I.; Trzebicka, B.; Muller, A.H.E.; Dworak, A.; Tsvetanov, C.B. Thermosensitive water-soluble copolymers with doubly responsive reversibly interacting entities. Prog. Polym. Sci. 2007, 32, 1275-1343. [CrossRef]

47. Winnik, M.; Yekta, A. Associative polymers in aqueous solution. Curr. Opin. Colloid Interface Sci. 1997, 2, 424-436. [CrossRef]

48. Hoogenboom, R. Poly (2-oxazoline) s: A polymer class with numerous potential applications. Angew. Chem. Int. Ed. 2009, 48, 7978-7994. [CrossRef]

49. Kratochvil, P. Classical Light Scattering from Polymer Solution, 1st ed.; Elsevier: Amsterdam, The Netherlands, 1987 ; pp. 1-346.

50. Schärtl, W. Light Scattering from Polymer Solutions and Nanoparticle Dispersions, 1st ed.; Springer: Berlin, Germany, $2007 ;$ pp. 1-187. 